Original Article

\title{
Effects of Yogic Exercises on Life Stress and Blood Glucose Levels in Nursing Students
}

\author{
SANG Dol KIM ${ }^{1)}$ \\ 1) Department of Nursing, College of Health Science, Kangwon National University: 346 Hwangjo-gil, \\ Dogye-eup, Samcheok-si, Gangwon-do 245-907, Republic of Korea
}

\begin{abstract}
Purpose] This study was performed to investigate the effects of yogic exercises on life stress and blood glucose levels in nursing students. [Subjects and Methods] The study was a randomized controlled trial. Twenty-seven undergraduate nursing students were randomly selected, with 12 assigned to an exercise group and 15 assigned to a control group. The yogic exercises intervention was undertaken for 60 minutes one day a week for 12 weeks. It consisted of physical exercise (surya namaskara) combined with relaxation and meditation (shavasana and yoga nidra). Life stress was measured by the Life Stress Scale for College Students, and postprandial blood glucose levels were measured with a digital glucometer. [Results] The exercise group measurements were significantly decreased in both life stress and postprandial blood glucose levels compared with the control group. [Conclusion] These findings indicate that yogic exercises would reduce life stress and lower postprandial blood glucose levels in nursing students.
\end{abstract}

Key words: Yogic exercise, Stress, Blood glucose

(This article was submitted Jul. 18, 2014, and was accepted Aug. 24, 2014)

\section{INTRODUCTION}

Stress is a multidimensional and universal phenomenon. Stress in nursing students is common and is process oriented. Nursing students are constantly under various stressors such as academic performance, isolation from the group, change in environment, change in food type, irregular diet, clinical challenges, economic problems, future prospects, problems with the value system of current society, self-expectations, and expectations from family and peers etc ${ }^{1-6)}$ If these stressors are not managed properly, they can have negative effects on the physical and psychological health of nursing students ${ }^{1-3)}$. Furthermore, these problems can cause academic failure and/or limited growth as a valuable employee ${ }^{2,4,7)}$. Therefore, it is necessary to put in place various activities and behaviors to prevent and reduce life stress in nursing students ${ }^{4,6-7)}$.

All these stressors have adverse effects on the autonomic nervous system, pineal and hypothalamic-pituitary-adrenal axis that interrupt the healthy operation of the homeostatic mechanisms of the body ${ }^{8)}$. This has damaging effects on various parameters of the body, and one of the common parameters is blood glucose ${ }^{2}$. It is observed that stress in creases both short-term and long-term blood glucose levels, and if it increases one or both of them beyond the normal

Corresponding author. Sang Dol Kim (E-mail: nu11110@, kangwon.ac.kr)

(C2014 The Society of Physical Therapy Science. Published by IPEC Inc. This is an open-access article distributed under the terms of the Creative Commons Attribution Non-Commercial No Derivatives (by-ncnd) License $<$ http://creativecommons.org/licenses/by-nc-nd/3.0/>. limits, stress can cause persistent high blood glucose levels, resulting in diabetes mellitus ${ }^{2)}$.

There are various ways to reduce stress, and one of them is yoga. Yoga, which integrates various postures, breathing exercises, and meditation, is beneficial in reducing stress. The mechanisms by which yoga influences well-being are likely complex biochemical and physiological mechanisms consisting of reduced sympathetic nervous tone, activation of antagonistic neuromuscular systems, and stimulation of the limbic system ${ }^{9}$. Therefore, yoga has been reported to lower levels of sympathetic hormones. That is to say, breathing exercises during yoga practice reduce sympathetic tone, increases parasympathetic activity, and help to reduce stress in yoga practictioners ${ }^{10}$. Meditation also brings about a hypometabolic state and reduces stress induced by sympathetic overactivity ${ }^{11)}$.

Also, yogic exercise has a direct influence on pancreatic secretion by rejuvenation of the pancreatic cells through alternate abdominal contractions and relaxation ${ }^{12,13)}$, and yogic exercise reduces blood glucose levels due to muscular exercise and relaxation ${ }^{12,13)}$. The dynamic stretching of the body during yoga asanas is postulated to rejuvenate pancreatic cells, increase insulin secretion, and hence correct the impaired insulin secretion in chronic diabetes ${ }^{14)}$. Ultimately, yoga practice has been proven to affect mental balance of an individual by allying apprehension and stress and bringing about hormonal balance and feelings of well-being ${ }^{2)}$.

In previous studies, researchers have indicated that yoga intervention played an effective role in decreasing stress and improving general well-being in medical students ${ }^{2,15)}$. In spite of its known positive effects on physical and psychological variables, no studies have been conducted with 
Table 1. Yogic exercise process

\begin{tabular}{lll}
\hline Step 1: surya namaskara $(20 \mathrm{~min} / 10$ cycles) & Step 2: shavasana $(5 \mathrm{~min})$ & Step 3: yoga nidra $(35 \mathrm{~min} / 1 \mathrm{cycle})$ \\
\hline (postures and breathing exercise) & (relaxation) & (meditation and relaxation) \\
\hline 1. Pranamasana (prayer pose) & 1. Shavasana (corpse pose) & 1. Resolve \\
2. Hasta Utthanasana (raised arms pose) & & 2. Rotation of consciousness \\
3. Padahastasana (hand to foot pose) & & 3. Awareness of the breath \\
4. Ashwa Sanchalanasana (equestrian pose) & & 4. Feeling and sensation \\
5. Parvatasana (mountain pose) & 5. Visualization \\
6. Ashtanga Namaskara (salute with eight part) & 6. Ending the practice with resolve \\
7. Bhujangasana (cobra pose) & \\
8. Parvatasana (mountain pose) & \\
9. Ashwa Sanchalanasana (equestrian pose) & & \\
10. Padahastasana (hand to foot pose) & & \\
11. Hasta Utthanasana (raised arms pose) & & \\
12. Pranamasana (prayer pose) & \\
\hline
\end{tabular}

yogic programs to manage nursing students' life stress. Hence, the purpose of this randomized controlled trial study was to evaluate the effect of yogic exercises on life stress and biochemical markers of stress such as blood glucose levels in nursing students.

\section{SUBJECTS AND METHODS}

This study was a randomized controlled trial. The subjects of this study were 27 healthy female undergraduate nursing students aged 20-23 years with no medical diseases, no history of drug abuse, and no experience with yoga exercise. Participants having a family history of diabetes mellitus were excluded from the study. The participants were recruited by using our nursing department's Internet homepage. The subjects were all volunteer nursing students. All participants received detailed information on the purpose and usefulness of this study and were provided a written consent form. After the participants signed the informed consent form, they were randomly assigned by a random permuted block design using a random number table, to 1 of 2 groups, either the yoga exercise $(n=15)$ or control group $(n=15)$. Twenty-seven subjects completed the entire study, 12 in the yoga exercise group and 15 in the control group. Three subjects dropped out of the study before completing the posttest due to personal reasons. The institutional review board of Kangwon National University approved this study. Demographic information, Life Stress Scale, and postprandial blood glucose levels were measured as pretest data. The Life Stress Scale and postprandial blood glucose levels were also measured as posttest data.

Life Stress was measured by the Life Stress Scale for College Students ${ }^{16)}$. This instrument consisted of 50 items scored using a 4 -point Likert scale $(0=$ never, $3=$ very often) measuring sources of life stress in 8 subscales-economy, lover, faculty, family, the future, values, grades, and friends. A higher score indicates a higher level of perceived stress. In this study, the internal consistency (Cronbach's alpha) of the Life Stress Scale was 0.93.

After completing Life Stress Scale surveys, postprandial blood glucose levels were measured as a stress-related biomarker. Measurements were taken from the participants both before commencement of the study and also after the yogic intervention was over. Postprandial blood glucose levels were measured with a digital glucometer (AccuChek. Sr. no-CN55303545723, Roche Diagnosis, Indianapolis, IN, USA).

Yogic exercises were conducted for about one hour, once a week for 12 weeks. The yoga instructor was certificated by Bihar Yoga Bharati in India. The yogic exercises were done in the Department of Nursing. Cyclic form yoga exercises were chosen because of the availability of scientific studies on this type of yoga ${ }^{17,18)}$. Cyclic yoga exercises refers to surya namaskara and yoga nidra. Surya namaskara translates as "sun salutations," and this type of yoga is composed of 12 postures and breathing exercises. Also yoga nidra, which means "psychic sleep," is a specific yogic relaxation and meditation practice ${ }^{19)}$. The cyclic yoga performed in this study consisted of the following practices (Table 1). Under the guidance and supervision of the yoga expert, after practicing 10 cycles of surya namaskara for 20 minutes, the subjects performed the shavasana pose for 5 minutes of relaxation. Finally, the subjects performed yoga nidra. Yoga nidra is performed in the shavasana pose. It has several steps, such as resolve, rotation of consciousness, awareness of the breath, feeling and sensation, visualization, and ending the practice with resolve.

Statistical analyses were conducted using the SAS program (version 9.1) for Windows. All data are presented as the mean $\pm \mathrm{SD}$. A t test was used to test for the homogeneity of demographic and clinical characteristics between the exercise and control group. Significant differences between groups were determined using unpaired t tests. Significant differences within groups were determined using paired $t$ tests. The level of statistical significance was considered to be a probability value of less than 0.05 .

\section{RESULTS}

No significant differences in age were found between the yoga group and the control group (Table 2). There were no significant differences in the pre-intervention Life Stress 
Table 2. Homogeneity test for age, life stress, and blood glucose level between the experimental and control group

\begin{tabular}{lcc}
\hline \multicolumn{1}{c}{ Variables } & $\begin{array}{c}\text { Experimental } \\
\text { group Mean } \pm \text { SD }\end{array}$ & $\begin{array}{c}\text { Control group } \\
\text { Mean } \pm \text { SD }\end{array}$ \\
\hline Age (years) & $21.0 \pm 0.2$ & $21.0 \pm 0.3$ \\
Life stress (score) & $1.6 \pm 0.3$ & $1.6 \pm 0.3$ \\
Economy & $1.6 \pm 0.5$ & $1.7 \pm 0.5$ \\
Lover & $1.3 \pm 0.4$ & $1.4 \pm 0.4$ \\
Faculty & $1.2 \pm 0.8$ & $1.3 \pm 0.8$ \\
Family & $1.3 \pm 0.4$ & $1.2 \pm 0.4$ \\
Future & $2.0 \pm 0.4$ & $1.9 \pm 0.3$ \\
Value & $1.8 \pm 0.6$ & $1.9 \pm 0.5$ \\
Grades & $2.4 \pm 0.4$ & $2.2 \pm 0.5$ \\
Friend & $1.3 \pm 0.4$ & $1.1 \pm 0.3$ \\
PPG (mg/dl) & $90.0 \pm 11.5$ & $89.6 \pm 9.9$ \\
\hline
\end{tabular}

PPG: postprandial blood glucose, SD: standard deviation

Scale score or pre-intervention postprandial blood glucose level between the two groups (Table 2).

The Life Stress Score significantly differed between the 2 groups (yoga group vs. control group, $\mathrm{p}<0.001$ ) and over time (pretest vs. posttest, $\mathrm{p}<0.001$ ). For the yoga group, the mean post-intervention Life Stress score (mean $\pm \mathrm{SD}$, $0.77 \pm 0.49$ ) was significantly decreased compared with the mean pre-intervention Life Stress score (mean \pm SD, $1.6 \pm$ 0.3). Of the Life Stress subscales, the score for the grades subscale was the highest. The Life Stress subscale scores of economy, lover, family, the future, values, grades, and friends were decreased significantly in the yoga group after the yogic exercises, respectively (Table 3 ).

The postprandial blood glucose level significantly differed between the 2 groups (yoga group vs. control group, $\mathrm{p}<0.001$ ) and over time (pretest vs. posttest, $\mathrm{p}<0.05$ ). For the yoga group, the mean post-intervention postprandial blood glucose level (mean $\pm \mathrm{SD}, 81.3 \pm 8.7$ ) was significantly decreased compared with the mean pre-intervention postprandial blood glucose level (mean $\pm \mathrm{SD}, 90.0 \pm 11.4$ ). For the control group, the mean post-intervention postprandial blood glucose level (mean $\pm \mathrm{SD}, 103.4 \pm 8.2$ ) was significantly increased compared with the mean pre-intervention postprandial blood glucose level (mean $\pm \mathrm{SD}, 89.6 \pm 9.9$ ) (Table 3).

\section{DISSCUSSION}

As shown in the study results, after 12 weeks of yogic exercises, Life Stress Scale scores were significantly decreased compared with those before starting yoga practice. Additionally, nursing students in the yoga exercise group had a significant decrease in their stress levels over this 12 week period, while those in the control group had an increase in their stress levels. These findings are similar to the findings of Simard and Henry, who found that Perceived Stress Scale levels significantly decreased from baseline to mid-term, an improvement that persisted to the end of the intervention $^{15}$. They assessed the impact of a short yoga intervention on female medical students' health for a 16-
Table 3. Effects of yogic exercises on life stress and postprandial blood glucose level

\begin{tabular}{|c|c|c|c|c|}
\hline \multicolumn{2}{|l|}{ Group } & \multirow{2}{*}{$\begin{array}{c}\text { Pretest } \\
\text { Mean } \pm \text { SD }\end{array}$} & \multirow{2}{*}{$\begin{array}{c}\text { Posttest } \\
\text { Mean } \pm \text { SD }\end{array}$} & \multirow{2}{*}{$\begin{array}{c}\text { Difference } \\
\text { (Posttest- } \\
\text { pretest) } \\
\text { Mean } \pm \text { SD }\end{array}$} \\
\hline & & & & \\
\hline \multirow{2}{*}{$\begin{array}{l}\text { Life stress } \\
\text { (score) }\end{array}$} & Yoga & $1.6 \pm 0.3$ & $0.7 \pm 0.4^{* * *}$ & $-0.8 \pm 0.6^{* * *}$ \\
\hline & Control & $1.6 \pm 0.3$ & $1.7 \pm 0.2$ & $0.1 \pm 0.3$ \\
\hline \multirow[t]{2}{*}{ Economy } & Yoga & $1.6 \pm 0.5$ & $0.6 \pm 0.5^{* * *}$ & $-1.0 \pm 0.6^{* * *}$ \\
\hline & Control & $1.7 \pm 0.5$ & $1.9 \pm 0.5$ & $0.1 \pm 0.5$ \\
\hline \multirow[t]{2}{*}{ Lover } & Yoga & $1.2 \pm 0.4$ & $0.5 \pm 0.5^{* *}$ & $-0.7 \pm 0.7^{* *}$ \\
\hline & Control & $1.4 \pm 0.4$ & $1.5 \pm 0.6$ & $0.1 \pm 0.7$ \\
\hline \multirow[t]{2}{*}{ Faculty } & Yoga & $1.1 \pm 0.7$ & $0.1 \pm 0.2^{* * *}$ & $-1.0 \pm 0.7$ \\
\hline & Control & $1.2 \pm 0.8$ & $0.6 \pm 0.7$ & $-0.6 \pm 1.1$ \\
\hline \multirow[t]{2}{*}{ Family } & Yoga & $1.2 \pm 0.3$ & $0.5 \pm 0.5^{* *}$ & $-0.7 \pm 0.6^{* * *}$ \\
\hline & Control & $1.2 \pm 0.4$ & $1.4 \pm 0.4$ & $0.1 \pm 0.4$ \\
\hline \multirow[t]{2}{*}{ Future } & Yoga & $2.0 \pm 0.3$ & $1.1 \pm 0.7^{* *}$ & $-0.8 \pm 0.8^{* * *}$ \\
\hline & Control & $1.8 \pm 0.3$ & $2.1 \pm 0.3$ & $0.2 \pm 0.4$ \\
\hline \multirow[t]{2}{*}{ Values } & Yoga & $1.8 \pm 0.5$ & $0.7 \pm 0.6^{* * *}$ & $-1.0 \pm 0.7 * * *$ \\
\hline & Control & $1.9 \pm 0.5$ & $2.2 \pm 0.3$ & $0.2 \pm 0.6$ \\
\hline \multirow[t]{2}{*}{ Grades } & Yoga & $2.4 \pm 0.4$ & $1.6 \pm 0.7^{*}$ & $-0.7 \pm 0.8^{* * *}$ \\
\hline & Control & $2.2 \pm 0.5$ & $2.6 \pm 0.3$ & $0.3 \pm 0.5$ \\
\hline \multirow[t]{2}{*}{ Friends } & Yoga & $1.2 \pm 0.3$ & $0.6 \pm 0.5^{* *}$ & $-0.6 \pm 0.6^{* * *}$ \\
\hline & Control & $1.1 \pm 0.3$ & $1.2 \pm 0.3$ & $0.1 \pm 0.3$ \\
\hline \multirow{2}{*}{$\begin{array}{l}\text { PPG } \\
(\mathrm{mg} / \mathrm{dl})\end{array}$} & Yoga & $90.0 \pm 11.4$ & $81.3 \pm 8.7^{* *}$ & $-8.7 \pm 7.5^{* * *}$ \\
\hline & Control & $89.6 \pm 9.9$ & $103.4 \pm 8.2 * *$ & $13.8 \pm 13.7$ \\
\hline
\end{tabular}

${ }^{*} \mathrm{p}<0.05 ; * * \mathrm{p}<0.01 ; * * * \mathrm{p}<0.001 ;$ PPG: postprandial blood glucose level, SD: standard deviation

week period. They also pointed out that a yoga intervention may be effective in decreasing stress and improving general well-being in medical students. Besides, the findings of Beets \& Mitchell indicated that despite short yoga program exposure, acute changes in mental health indicators such as stress were observed ${ }^{20)}$. Similarly, the findings of Yoshihara et al. suggested that yoga can improve mental health status and has implications for the prevention of psychosomatic symptoms in healthy women ${ }^{17}$ ). In addition, Sharma systematically reviewed 17 articles related to yoga for stress management ${ }^{8)}$. As a result, they reported that of the 17 studies, 12 demonstrated positive changes in psychological or physiological outcomes related to stress. Like the previous studies, the present study also supports the paradigm that yoga exercise can have beneficial effects in reducing psychological problems such as stress in nursing students.

Of the Life Stress subscales in this study, the grades subscale had the highest score. This result is inconsistent with the concept that academic factors are a greater perceived cause of stress in nursing students, ${ }^{1,5,6)}$. Over the past 2 decades, many forms of intervention have been suggested to help nursing students with their stress. Most recently, one researcher recommended biofeedback, humor, peer instructors, mentors, and mindfulness training interventions for stress centered around academic challenges in nursing students $\left.^{2}, 5,6,21-23\right)$. However, no recent studies have been conducted with a new generation of yoga exercises to help 
reduce nursing students' stress. Ultimately, these findings suggest that the nursing students in the yoga exercise group were able to control the same level of stress over the 12week period even though they experienced more stressors and demands from their academic conditions. It is very important for nurse educators to help nursing students manage their stress in order to prevent additional problems.

In the present study, the postprandial blood glucose level was measured as a biochemical indicator of stress. Fasting blood sugar levels could not be checked because of the time of the yoga class as the participants' personal situations. The yoga class started at 5 PM every Thursday.

After practicing yoga for 12 weeks, postprandial blood glucose levels were significantly decreased in the yoga group. This finding is similar to that of Shende et al., who found that both fasting and postprandial blood glucose levels were significantly improved in the yoga group, whereas there was no significant improvement in the postprandial blood glucose levels in their control group not practicing yoga pranayama ${ }^{4}$. They assessed the effect of pranayama on the blood glucose level of 60 medical students and found that a short-term intervention of yogic exercise helps in reducing the stress in medical students, which is reflected by improvement in both fasting and postprandial blood glucose levels. They also emphasized that the beneficial effects of yoga on fasting and postprandial blood glucose levels are well documented. As stated, most of these studies have been done on patients with known diseases. However, there is very little data available on the effect of yoga exercise composed of surya namaskara (which means sun salutations) and yoga nidra (which means psychic sleep) on the blood glucose levels in healthy subjects. The findings of the present study also support those of Jensen, Stevens, and Kenny, who stated that yoga nidra is related to psychoneuro-physiological parameters ${ }^{24)}$. Numerous studies have shown yoga to have an immediate downregulating effect on both the pineal and hypothalamic-pituitary-adrenal axis responses to stress ${ }^{12-15)}$. The performance of asana led to increased sensitivity of the B cells of the pancreas to the glucose signal. It also increased the sensitivity of the progressive long-term effect of asanas. Therefore, it was also found that brief yoga-based relaxation training normalizes the functions of the autonomic nervous system ${ }^{15}$. As shown in previous studies, the findings of the present study suggest that yogic exercises can improve stress and stress biomarkers in nursing students. However, follow-up studies will be needed to evaluate the effect on biochemical parameters of stress such as cortisol and blood glucose in nursing students. To my knowledge, this is the first study to demonstrate the effect of yoga exercise on the blood glucose level of healthy nursing students.

The present study has some limitations. Use of only female subjects meant that we could not make comparisons between males and females. The participants were not on a strict and uniform diet plan, and this may have influenced the study results. Despite these limitations, these findings suggest that cyclic yoga exercise can improve not only the score of Life Stress, but also the postprandial blood glucose level in nursing students.

\section{REFERENCES}

1) Choi HJ, Lee EJ: Meditation effects of self-efficacy between academic stress and college adjustment in first year nursing students. J Korean Acad Fundam Nurs, 2012, 19: 261-268. [CrossRef]

2) Gibbons C, Dempster M, Moutray M: Stress, coping and satisfaction in nursing students. J Adv Nurs, 2011, 67: 621-632. [Medline] [CrossRef]

3) Song YS: Effects of a meditation program on stressful life events and the quality of life with nursing students. J Korean Data Analy Soci, 2013, 15: 965-974.

4) Shende V, Waghmare S, Oawar S, et al.: Effect of pranayama on blood glucose level in medical students: A case control study. Int J Res Health Sci, 2013, 1: 209-212.

5) Ratanasiripong P, Ratanasiripong N, Kathalae D: Biofeedback intervention for stress and anxiety among nursing students: a randomized controlled trial. ISRN Nurs, 2012, doi: 10.5402/2012/827972.

6) Yeom YR, Choi KB: The effect of mindfulness meditation programs on nursing college students' perceived stress, depression, and self-efficacy. J East-West Nurs Res, 2013, 19: 104-113. [CrossRef]

7) Yazdani M, Rezaei S, Pahlavanzadeh S: The effectiveness of stress management training program on depression, anxiety and stress of the nursing students. Iran J Nurs Midwifery Res, 2010, 15: 208-215. [Medline]

8) Sharma M: Yoga as an alternative and complementary approach for stress management: a systematic review. J Evid Based Complement Altern Med, 2014, 19: 59-67 [CrossRef]. [Medline]

9) Riley D: Hatha yoga and the treatment of illness. Altern Ther Health Med, 2004, 10: 20-21. [Medline]

10) Damodaran A, Malathi A, Patil N, et al.: Therapeutic potential of yoga practices in modifying cardiovascular risk profile in middle aged men and women. J Assoc Physicians India, 2002, 50: 633-640. [Medline]

11) Bhattacharya S, Pandey US, Verma NS: Improvement in oxidative status with yogic breathing in young healthy males. Indian J Physiol Pharmacol, 2002, 46: 349-354. [Medline]

12) Singh S, Kyizom T, Singh KP, et al.: Influence of pranayamas and yogaasanas on serum insulin, blood glucose and lipid profile in type 2 diabetes. Indian J Clin Biochem, 2008, 23: 365-368. [Medline] [CrossRef]

13) Mahapure HH, Shete SU, Bera TK: Effect of yogic exercise on super oxide dismutase levels in diabetics. Int J Yoga, 2008, 1: 21-26. [Medline] [CrossRef]

14) Sahay BK: Role of yoga in diabetes. J Assoc Physicians India, 2007, 55: 121-126. [Medline]

15) Simard AA, Henry M: Impact of a short yoga intervention on medical students' health: a pilot study. Med Teach, 2009, 31: 950-952. [Medline] [CrossRef]

16) Kim KG, Kim KH, Lee JS: Development of revised life stress scale for college students. Korean J Health Psychol, 2000, 5: 316-335.

17) Yoshihara K, Hiramoto T, Oka T, et al.: Effect of 12 weeks of yoga training on the somatization, psychological symptoms, and stress-related biomarkers of healthy women. Biopsychosoc Med, 2014, 8: 1-9 [CrossRef]. [Medline]

18) Satyanada SS: Asana Pranayama Mudra Bandha. India: Bihar Yoga Bharati Yoga Publication Trust, 2006, pp 161-172.

19) Satyanada SS: Yoga nidra. India: Bihar Yoga Bharati Yoga Publication Trust, 2006, pp 69-89.

20) Beets MW, Mitchell E: Effects of yoga on stress, depression, and healthrelated quality of life in a nonclinical, bi-ethnic sample of adolescents: a pilot study. Hisp Health Care Int, 2010, 8: 47-53. [CrossRef]

21) Kang YS, Choi SY, Ryu E: The effectiveness of a stress coping program based on mindfulness meditation on the stress, anxiety, and depression experienced by nursing students in Korea. Nurse Educ Today, 2009, 29: 538-543 [CrossRef]. [Medline]

22) Shaban IA, Khater WA, Akhu-Zaheya LM: Undergraduate nursing students' stress sources and coping behaviours during their initial period of clinical training: a Jordanian perspective. Nurse Educ Pract, 2012, 12: 204-209. [Medline] [CrossRef]

23) Yazdani M, Esmaeilzadeh M, Pahlavanzadeh S, et al.: The effect of laughter Yoga on general health among nursing students. Iran J Nurs Midwifery Res, 2014, 19: 36-40. [Medline]

24) Jensen PS, Stevens PJ, Kenny DT: Respiratory patterns in students enrolled in schools for disruptive behaviour before, during, and after yoga nidra relaxation. J Child Fam Stud, 2012, 21: 667-681. [CrossRef] 